\title{
IMPLEMENTASI SISTEM INFORMASI AKADEMIK PESANTREN IMMIM PUTRA BERBASIS WEB
}

\author{
Ahmad Ariyadi Yusuf ${ }^{1)}$,Dr. H. Kamaruddin Tone, M.M ${ }^{2)}$, Mega Orina Fitri, S.T., M.T ${ }^{3)}$ \\ ${ }^{1,2}$ Balai Besar Pengkajian dan Pengembangan Komunikasi dan Informatika Makassar \\ ${ }^{1,2}$ Jl. Prof. Dr. Abdurrahman Basalamah II No.25, Makassar, 90123, Telp/Fax: 0411-4460084 \\ ${ }^{3}$ Fakultas Sosial dan Ilmu Politik, Universitas Hasanuddin \\ ${ }^{3}$ Jl. Perintis Kemerdekaan km. 10 Tamalanrea, Makassar, 90245, Telp/Fax: 0411-586001 \\ E-mail: email1@domain.ekstensi ${ }^{1)}$,email2@domain.ekstensi ${ }^{2}$, email3@domain.ekstensi ${ }^{3)}$
}

\begin{abstract}
Abstrak - Pesantren IMMIM Putra merupakan lembaga pendidikan Islam berbasis pondok yang memiliki jumlah santri sebanyak 980 orang. Segala kegiatan dalam pengolahan data akademik, masih menggunakan teknik konvensional. Dengan kata lain masih menggunakan metode pengarsipan dalam bentuk buku atau kertas, hal ini mempunyai banyak kelemahan, seperti kertas mudah lapuk, data-data yang tidak mudah diubah setiap waktu, pencarian data yang sulit, dan penyampaian informasi yang tidak aktual. Pada penelitian ini menggunakan jenis penelitian deskriptif kualitatif dengan menggunakan metode pengumpulan data yaitu observasi dan wawancara. Adapun tools yang digunakan untuk merancang Sistem Informasi Akademik Pesantren IMMIM Putra menggunakan Unified Modeling Language dan tools untuk merancang basis data memakai Entity Relationalship Diagram. Sedangkan bahasa pemrograman yang dipakai menggunakan PHP dan MySQL serta pengujian aplikasi ini menggunakan metode Black Box. Penelitian ini menyimpulkan sistem yang dibangun dapat memudahkan dalam pengolahan data akademik santri, meningkatkan efisiensi dan efektifitas dalam pengolahan data akademik pesantren dan mempermudah proses pendaftaran santri baru serta informasi seputar akademik pesantren dapat diperoleh dengan mudah.
\end{abstract}

Kata Kunci : Sistem Informasi, Akademik, Pesantren Immim Putra, UML, ERD, Black Box

\section{Pendahuluan}

Pesantren

merupakan

lembaga

pendidikan, yang menampung peserta didik dan dibina agar memiliki kemampuan, kecerdasan, dan keterampilan sehingga tercapainya tujuan pendidikan. Pesantren IMMIM Putra Makassar adalah institusi pendidikan agama berbasiskan pondok yang mengatur segala hal yang berkaitan dengan penyelenggaraan pendidikan keagamaan.

Peraturan pesantren mengharuskan santri tinggal di pondok selama menempuh pendidikan di pesantren menyebabkan orang tua santri harus jauh-jauh datang ke pesantren untuk melihat hasil perkembangan akademik putranya. Pengelola pesantren memberikan informasi tentang perkembangan proses belajar santri di dalam pondok kepada orang tua dengan cara orang tua harus datang ke pondok pesantren untuk melihat perkembangan akademik putranya dikerenakan informasi yang diberikan orang tua santri masih dilakukan secara konvensional.

Perkembangan teknologi telah merambah ke dunia pendidikan yang berkembang dengan pesat membuat banyak kemudahan dalam melakukan kegiatan. Website salah satu dari perkembangan teknologi yang digunakan untuk bermacam macam guna menunjang pekerjaan, selain itu banyak juga operator jaringan komunikasi yang memberikan penawaran jasa komunikasi dengan harga yang relatif terjangkau.

Seiring dengan perkembangan teknologi peran sistem informasi juga sangat dibutuhkan agar dapat meningkatkan kinerja dan memungkinkan berbagai kegiatan dapat dilaksanakan dengan cepat, tepat, dan akurat sehingga akhirnya akan meningkatkan produktivitas manajemen pendidikan. Keberhasilan dalam meningkatkan efisiensi dan 
produktivitas bagi manajemen pendidikan akan ikut menentukan kelangsungan hidup lembaga pendidikan itu sendiri.

Dari uraian di atas menarik untuk melakukan penelitian dan pengembangan serta memberikan solusi untuk menangani permasalahan tersebut dengan cara memberikan suatu usulan rancangan sistem informasi

\section{Metodologi Penelitian}

Penelitian ini menggunakan jenis penelitian deskriptif kualitatif yang bertujuan untuk mendeskripsikan apa-apa yang saat ini berlaku. Di dalamnya terdapat upaya mendeskripsikan, mencatat, analisis dan menginterpretasikan kondisi yang terjadi untuk mengungkapkan proses-proses informasi dalam akademik pesantren yang digunakan sebagai dasar dalam perancangan sistem informasi dengan menerapkan tahap-tahap yang ada dalam SDLC (Hasan, 2002).

Adapun lokasi penelitian ini dilakukan di Pesantren IMMIM Putra Makassar yang beralamat di Jl. Perintis Kemerdekaan km.10 Tamalanrea Kota Makassar.

\section{Metode Pengumpulan Data}

\section{Observasi}

Observasi yang dilakukan yaitu mengamati secara langsung proses pengolahan akademik di sekolah untuk memperoleh gambaran yang jelas mengenai permasalahan yang diteliti.

\section{Wawancara}

Wawancara merupakan teknik pengumpulan data yang dilakukan melalui tatap muka dan tanya jawab langsung antara pengumpul data terhadap narasumber/sumber data.

\section{A. Instrumen Penelitian}

Adapun instrument penelitian yang digunakan dalam penelitan yaitu :

\section{Perangkat Keras}

Perangkat keras yang digunakan untuk mengembangkan dan menguji coba adalah

a. Laptop Lenovo $\mathrm{G} 400$ spesifikasi :

1) Processor Intel Pentium.

2) Hardisk $250 \mathrm{~GB}$.

\section{Perangkat Lunak}

Adapun perangkat lunak yang digunakan dalam aplikasi ini adalah sebagai berikut :

a. Sistem Operasi, Windows 7 Ultimate 32-bit.

b. Notepad ++.

c. Xampp.

d. Adobe Photoshop.

\section{Teknik Pengolahan dan Analisis Data}

\section{Pengolahan Data}

Pengolahan data diartikan sebagai proses mengartikan data-data lapangan yang sesuai dengan tujuan, rancangan, dan sifat penelitian. Metode pengolahan data dalam penelitian ini yaitu:

a. Reduksi data adalah mengurangi atau memilahmilah data yang sesuai dengan topik dimana data tersebut dihasilkan dari penelitian.

b. Koding data adalah penyusuaian data diperoleh dalam melakukan penelitian kepustakaan maupun penelitian lapangan dengan pokok pada permasalahan dengan cara memberi kode-kode tertentu pada setiap data tersebut.

\section{Analisis Data}

Teknik analisis data bertujuan menguraikan dan memecahkan masalah yang berdasarkan data yang diperoleh. Analisis yang digunakan adalah analisis data kualitatif. Analisis data kualitatif adalah upaya yang dilakukan dengan jalan mengumpulkan, memilah - milah, mengklasifikasikan, dan mencatat yang dihasilakan catatan lapangan serta memberikan kode agar sumber datanya tetap dapat ditelusuri.

\section{Metode Pengembangan Sistem}

Pada penelitian ini, metode pengembangan sistem yang digunakan adalah waterfall merupakan salah satu metode dalam SDLC (System Development Life Cycle) yang mempunyai ciri khas pengerjaan setiap fase dalam watefall harus diselesaikan terlebih dahulu sebelum melanjutkan ke fase selanjutnya. Metode waterfall adalah pengerjaan dari suatu sistem dilakukan secara berurutan atau secara linear.

Secara garis besar metode waterfall mempunyai langkah-langkah sebagai berikut : Analisa, Desain, Penulisan, Pengujian dan Penerapan serta Pemeliharaan (Kadir, 2003). 


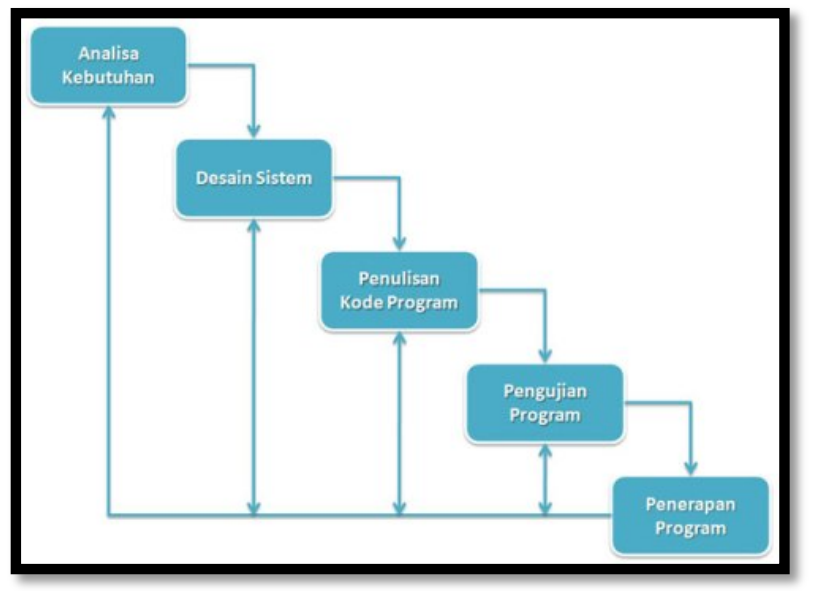

Gambar III. 1. Model Waterfall (Kadir, 2003).

\section{B. Pengujian dan Keabsahan Data}

Untuk Metode Pengujian yang dilakukan pada penelitian ini adalah metode pengujian langsung yaitu dengan menggunakan pengujian Black Box.

Digunakan untuk menguji fungsi-fungsi khusus dari perangkat lunak yang dirancang. Kebenaran perangkat lunak yang diuji hanya dilihat berdasarkan keluaran yang dihasilkan dari data atau kondisi masukan yang diberikan untuk fungsi yang ada tanpa melihat bagaimana proses untuk mendapatkan keluaran tersebut. Dari keluaran yang dihasilkan, kemampuan program dalam memenuhi kebutuhans pemakai dapat diukur sekaligus dapat diiketahui kesalahan-

kesalahannya.

Adapun hal-hal yang ingin dicapai / diuji pada aplikasi yang akan dibuat digambarkan pada tabel berikut :

\begin{tabular}{|c|c|c|c|c|}
\hline Aktor & Bagian menu & Test case & Data masukan & $\begin{array}{c}\text { Hasil yang } \\
\text { diharapkan }\end{array}$ \\
\hline \multirow{3}{*}{$\begin{array}{l}\text { Admin, } \\
\text { Pegawai, } \\
\text { Orang tua / } \\
\text { santri }\end{array}$} & \multirow{3}{*}{ Akses } & Log in & $\begin{array}{l}\text { Mengisi form } \\
\text { login kemudian } \\
\text { klik tombol Log in }\end{array}$ & $\begin{array}{l}\text { Masuk ke } \\
\text { halaman sesuai } \\
\text { level akun }\end{array}$ \\
\hline & & Log Out & $\begin{array}{l}\text { Menekan tombol } \\
\text { Log out }\end{array}$ & $\begin{array}{l}\text { Keluar dari } \\
\text { sistem }\end{array}$ \\
\hline & & $\begin{array}{l}\text { Ganti } \\
\text { password }\end{array}$ & $\begin{array}{l}\text { Pilih menu, input } \\
\text { password lama, } \\
\text { input password } \\
\text { baru }\end{array}$ & Password terganti \\
\hline \multirow{4}{*}{ Admin } & \multirow{4}{*}{$\begin{array}{l}\text { Data pegawai, } \\
\text { santri, } \\
\text { matapelajaran, } \\
\text { jadwal pelajaran, } \\
\text { PSB, ekskul dan } \\
\text { kelas }\end{array}$} & Lihat data & $\begin{array}{l}\text { pilih menu, tekan } \\
\text { tombol view, } \\
\text { mengisi data } \\
\text { pencarian, klik } \\
\text { search }\end{array}$ & $\begin{array}{l}\text { Melihat data } \\
\text { secara detail }\end{array}$ \\
\hline & & Input data & $\begin{array}{l}\text { Pilih menu data, } \\
\text { masukan data, } \\
\text { tekan tambah }\end{array}$ & Data tertambah \\
\hline & & Ubah data & $\begin{array}{l}\text { Pilih menu data, } \\
\text { targetkan data, } \\
\text { tekan edit, mengisi } \\
\text { form edit, tekan } \\
\text { tombol update }\end{array}$ & Data ter-update \\
\hline & & Hapus data & $\begin{array}{l}\text { Pilih menu, cari } \\
\text { data yang ingin } \\
\text { dihapus, tekan } \\
\text { tombol delete }\end{array}$ & Data terhapus \\
\hline \multirow{2}{*}{$\begin{array}{l}\text { Orang Tua } \\
\text { / Santri, } \\
\text { dan guru }\end{array}$} & Jadwal pelajaran & Lihat Jadwal & $\begin{array}{l}\text { Pilih menu, pilih } \\
\text { semester, kelas } \\
\text { dan tekan tombol } \\
\text { view } \\
\end{array}$ & $\begin{array}{l}\text { Menampilkan } \\
\text { jadwal pelajaran }\end{array}$ \\
\hline & Data santri & $\begin{array}{l}\text { Lihat data } \\
\text { santri }\end{array}$ & $\begin{array}{l}\text { Pilih menu data } \\
\text { santri, tekan } \\
\text { tombol view }\end{array}$ & $\begin{array}{l}\text { Menampilkan } \\
\text { profil, kelas, wali } \\
\text { kelas, dan } \\
\text { pembina santri }\end{array}$ \\
\hline $\begin{array}{l}\text { Orang Tua } \\
\text { / Santri, } \\
\text { guru, dan } \\
\text { BK }\end{array}$ & Data absensi & Lihat absensi & $\begin{array}{l}\text { Pilih menu } \\
\text { absensi, pilih } \\
\text { semester, dan } \\
\text { kelas } \\
\end{array}$ & $\begin{array}{l}\text { Menampilkan } \\
\text { absensi santri }\end{array}$ \\
\hline
\end{tabular}

\begin{tabular}{|c|c|c|c|c|}
\hline \multirow{3}{*}{ Guru } & & Input absensi & $\begin{array}{l}\text { Pilih menu } \\
\text { absensi, pilih } \\
\text { kelas, masukan } \\
\text { kehadiran tiap } \\
\text { santri klik save }\end{array}$ & $\begin{array}{l}\text { Absensi } \\
\text { tertambah }\end{array}$ \\
\hline & \multirow{3}{*}{$\begin{array}{l}\text { Data nilai } \\
\text { akademik, ekskul }\end{array}$} & Input data & $\begin{array}{l}\text { Pilih menu, pilih } \\
\text { kelas, cari santri, } \\
\text { masukan data, klik } \\
\text { save }\end{array}$ & Data tertambah \\
\hline & & Ubah data & $\begin{array}{l}\text { Pilih menu, pilih } \\
\text { kelas, cari santri, } \\
\text { klik edit, ubah } \\
\text { data }\end{array}$ & Data terubah \\
\hline \multirow{2}{*}{$\begin{array}{l}\text { Orang Tua } \\
\text { / Santri, } \\
\text { BK }\end{array}$} & & Lihat data & $\begin{array}{l}\text { Pilih menu, pilih } \\
\text { semester, klik } \\
\text { view }\end{array}$ & $\begin{array}{l}\text { Menampilkan } \\
\text { data }\end{array}$ \\
\hline & \multirow{3}{*}{ Data pelanggaran } & Lihat data & $\begin{array}{l}\text { Pilih menu, pilih } \\
\text { semester, klik } \\
\text { view }\end{array}$ & $\begin{array}{l}\text { Menampilkan } \\
\text { data }\end{array}$ \\
\hline \multirow{2}{*}{ BK } & & Input data & $\begin{array}{l}\text { Pilih menu, pilih } \\
\text { kelas, cari santri, } \\
\text { masukan data, klik } \\
\text { save }\end{array}$ & Data tertambah \\
\hline & & Ubah data & $\begin{array}{l}\text { Pilih menu, pilih } \\
\text { kelas, cari santri, } \\
\text { klik edit, ubah } \\
\text { data }\end{array}$ & Data terubah \\
\hline \multirow{2}{*}{ Pembina } & \multirow{3}{*}{ Data hafalan } & Input data & $\begin{array}{l}\text { Pilih menu } \\
\text { hafalan, pilih } \\
\text { kelas, cari santri, } \\
\text { masukan data, klik } \\
\text { save }\end{array}$ & Data tertambah \\
\hline & & Edit data & $\begin{array}{l}\text { Pilih menu } \\
\text { hafalan, pilih } \\
\text { kelas, cari santri, } \\
\text { klik edit, ubah } \\
\text { data }\end{array}$ & Data terubah \\
\hline Orang tua & & Lihat data & $\begin{array}{l}\text { Pilih menu } \\
\text { hafalan, pilih } \\
\text { semester, klik } \\
\text { view }\end{array}$ & $\begin{array}{l}\text { Menampilkan } \\
\text { data }\end{array}$ \\
\hline \multirow{2}{*}{$\begin{array}{l}\text { Calon } \\
\text { santri }\end{array}$} & $\begin{array}{l}\text { Pendaftaran santri } \\
\text { baru }\end{array}$ & Input data & $\begin{array}{l}\text { Masuk ke website, } \\
\text { klik daftar, } \\
\text { masukan data } \\
\text { yang disediakan }\end{array}$ & Santri terdaftar \\
\hline & Pengumuman psb & Lihat data & $\begin{array}{l}\text { Login psb, klik } \\
\text { pengumuman }\end{array}$ & $\begin{array}{l}\text { Menampilkan } \\
\text { hasil } \\
\text { pengumuman } \\
\text { kelulusan } \\
\end{array}$ \\
\hline
\end{tabular}

Tabel 1. Pengujian

\section{HASIl Dan PEMbahasan}

Implementasi antarmuka dari perangkat lunak dilakukan berdasarkan rancangan yang telah dilakukan. Implementasi ditampilkan dari screenshoot dari halaman website yang digunakan sebagai alat dan bahan penelitian yang telah dirincikan pada $B A B$ IV.

\section{a. Antarmuka halaman login utama}

Dalam halaman ini terdapat tampilan untuk memasukkan user name dan password. Selain itu terdapat layanan prosedur pendaftaran santri baru, dan pendaftran santri baru.

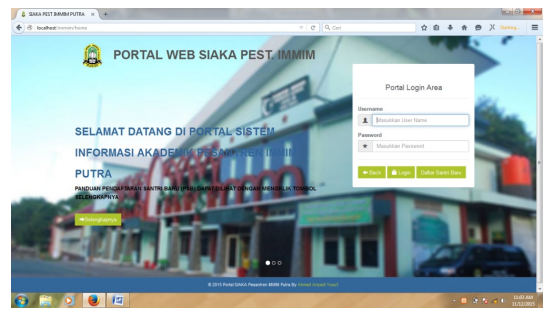

Gambar V. 1. Halaman Login.

b. Antarmuka halaman pendaftaran santri baru (PSB) 
Halaman web ini merupakan halaman registrasi santri baru, yang menampilkan pengisian formulir pendaftaran. Berikut ini antarmuka tampilannya :

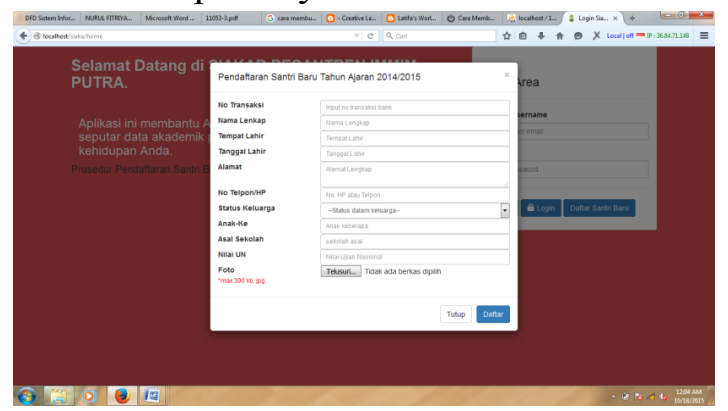

Gambar V. 2. Pendaftaran Santri Baru.

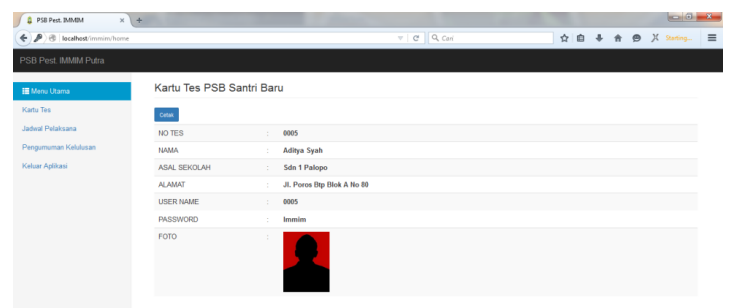

Gambar V. 3. Halaman Utama PSB.

Halaman portal psb di atas adalah halaman utama yang digunakan untuk melihat biodata pendaftaran calon santri baru, selain itu terdapat pencetakan kartu tes penerimaan santri baru.

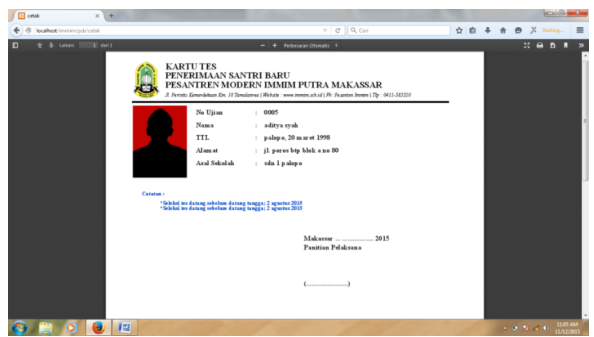

Gambar V. 4. Kartu Tes PSB.

Gambar di atas merupakan tampilan kartu tes penerimaan santri baru yang digunakan saat test tulis dan wawancara di pondok pesantren.

c. Antarmuka Halaman Administrator

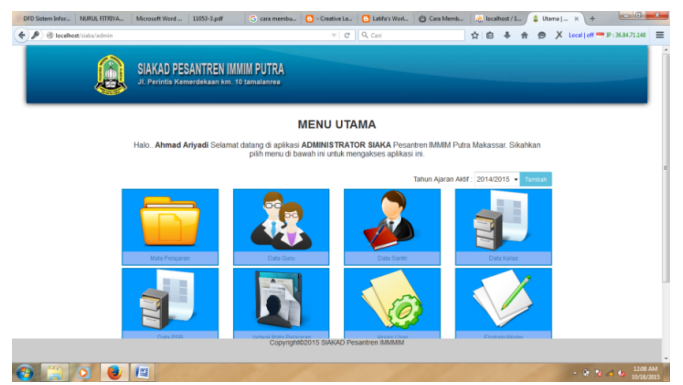

Gambar V. 5. Halaman Utama Admin.
Halaman di atas merupakan halaman yang ditampilkan setelah admin website melakukan login. Halaman ini berisi menu halaman-halaman admin. Halaman-halaman tersebut digunakan oleh admin untuk mengolah data website mulai dari data guru, santri, psb, jadwal pelajaran, absensi, nilai, pelanggaran, informasi, chating, dan pencetakan rapor santri.

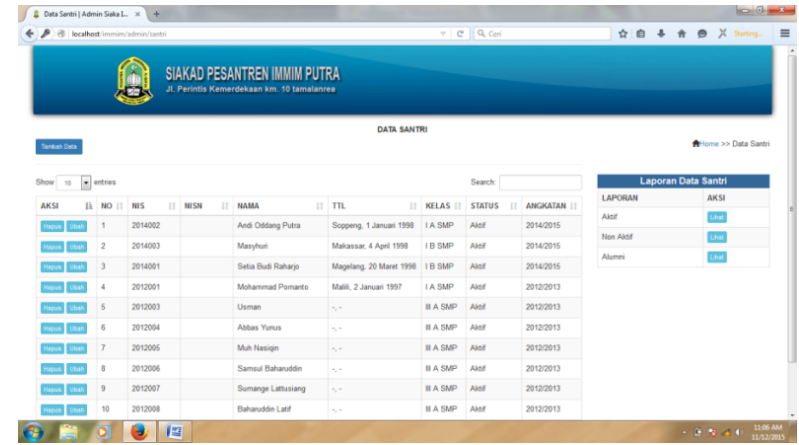

Gambar V. 6. Data Santri.

Halaman portal admin di atas digunakan untuk melihat informasi semua data santri, selain itu data dapat disortir yang terdiri atas santri aktif, non aktif dan alumni.

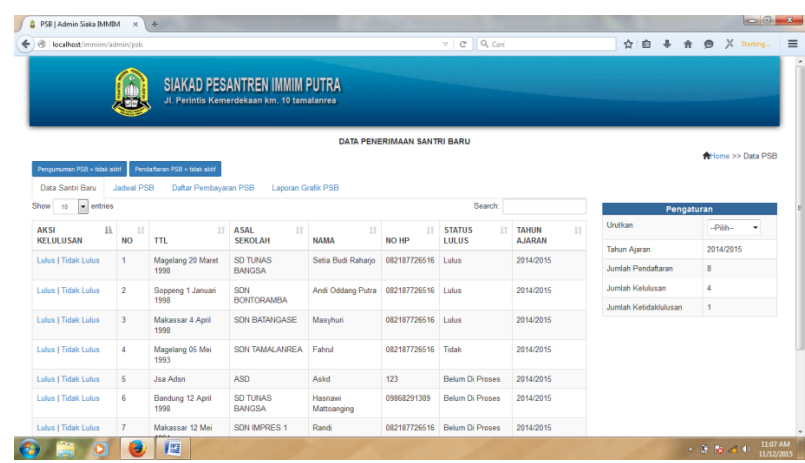

Gambar V. 7. Data PSB.

Halaman portal admin di atas digunakan untuk melihat semua data pendaftaran santri baru, selain itu terdapat juga informasi jadwal kegiatan psb, dan laporan grafik pendaftaran santri per tahun ajaran.

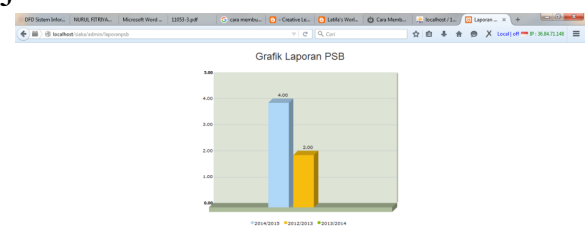

Gambar V. 8. Laporan Grafik PSB.

Halaman di atas merupakan halaman yang digunakan oleh admin website sistem informasi akademik untuk menampilkan laporan grafik psb per 
tahun ajaran berfungsi untuk pengambilan keputusan berikutnya.

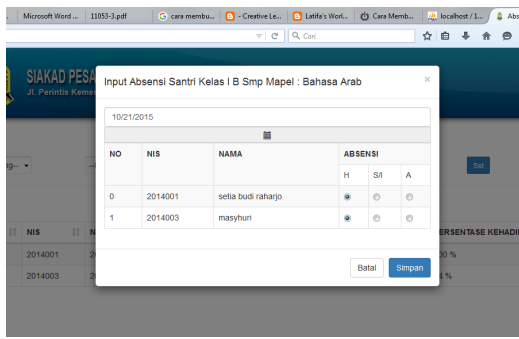

Gambar V. 9. Input Absensi Santri.

Halaman ini merupakan halaman yang dapat digunakan oleh admin website sistem informasi akademik untuk memasukkan, menghapus, dan mengubah data absensi santri yang ada di website.

\section{d. Halaman Portal Guru}

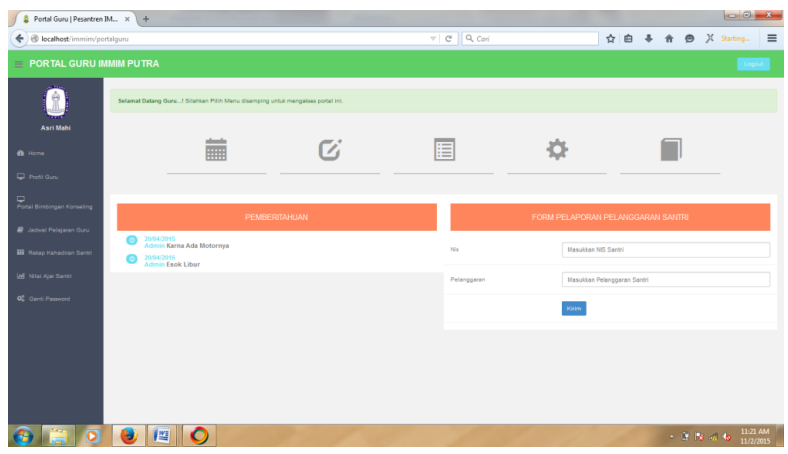

Gambar V. 10. Halaman Portal Guru.

Halaman di atas digunakan guru untuk melihat informasi dari admin selain itu terdapat form digunakan untuk pelaporan pelanggaran santri ke BK.

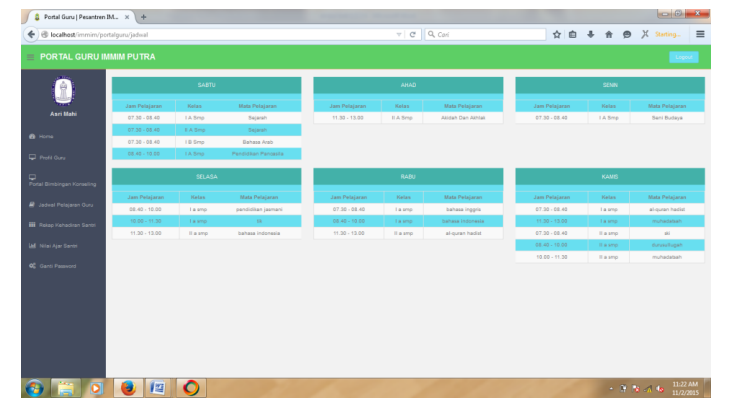

Gambar V. 11. Jadwal Mata Pelajaran Guru.

Halaman portal guru di atas digunakan guru untuk melihat informasi semua jadwal mata pelajaran yang diajarkan.

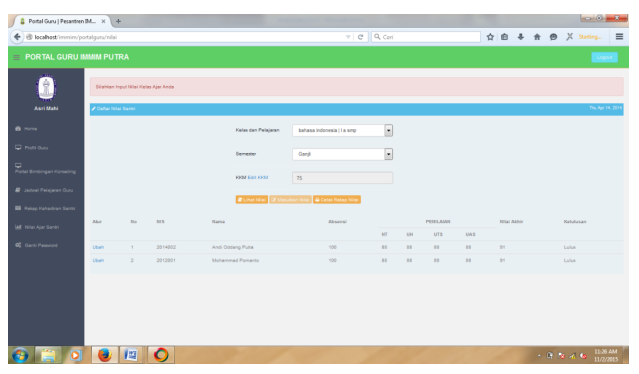

Gambar V. 12. Nilai Santri.

Halaman portal guru di atas digunakan guru untuk melihat, menambah, mengubah, dan menghapus nilai santri yang diajarkan oleh guru selain itu ada fasilitas untuk mencetak rekapan nilai santri.

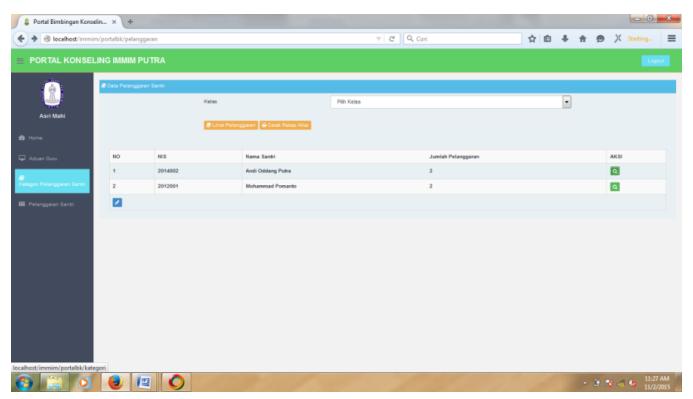

Gambar V. 13. Pelanggaran Santri.

Halaman portal BK di atas digunakan untuk memasukkan semua pelanggaran santri selain itu dapat juga melihat informasi pelanggaran santri beserta poinnya.

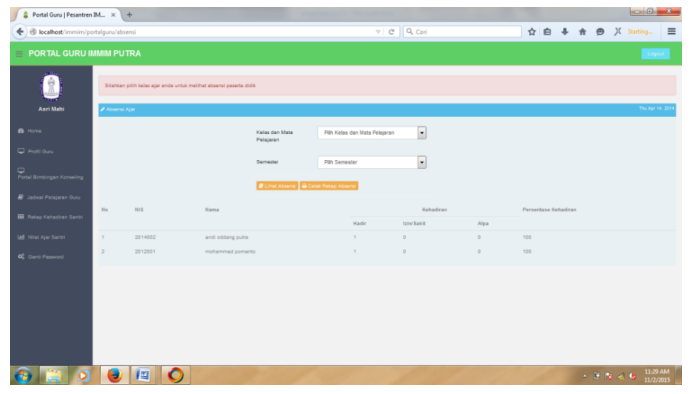

Gambar V. 14. Rekap Kehadiran Santri.

Halaman portal guru di atas digunakan guru untuk melihat informasi kehadiran santri selama proses belajar mengar.

\section{KESIMPULAN}

Berdasarkan hasil analisis sistem informasi akademik pada Pesantren IMMIM Putra Makassar, maka penulis mengambil kesimpulan bahwa :

1. Dengan adanya sistem informasi akademik ini, orang tua tidak harus datang lagi ke pesantren untuk melakukan proses 
pendaftaran santri baru dan melihat hasil akademik anaknya karena sistem memiliki portal khusus yang berisi informasi seputar akademik santri.

2. Proses pencarian dan pengolahan data santri, guru, kelas, pembagian jadwal pelajaran, absensi, nilai, dan pembuatan laporan menjadi lebih efektif dan efisien serta dapat diakses dimana saja dan kapan saja.

3. Dengan sistem informasi akademik ini pengambilan keputusan penilaian semakin cepat dan mudah karena sistem perhitungan penilaian sudah otomatis dan sudah disesuaikan dengan keputusan pesantren sehingga mengefisienkan waktu penilaian.

4. Adapun yang menjadi kekurangan dalam sistem yang dibangun yaitu sistem belum dapat menghasilkan laporan dalam bentuk $m s$. excel dan ms. word selain itu sistem belum dapat diintegrasikan antara sistem pembayaran pendaftaran santri dengan sistem informasi akademik yang dibangun.

\section{DAFTAR PUSTAKa}

Achyaruddin, Yazid. Sistem Informasi akademik berbasis android pada STIMIK Global Informatika Multi Data Palembang. Skripsi. Palembang: Fakultas Ilmu Komputer STIMIK Global Informatika Multi Data, 2014.

Jogiyanto. (2005). Pengenalan Komputer. Yogyakarta: Andi.

Mulyanto, A. (2009). Sistem Informasi Konsep dan Aplikasi. Yogyakarta: 2009.

Kadir, A. (2003). Pengenalan Sistem Informasi. Yogyakarta: Andi.

Al-Fattah, H. (2007). Analisi dan Perancangan Sistem Informasi. Yogyakarta: Andi.

Ladjamudin, A.-B. B. (2005). Analisis dan Desain Sistem Informasi. Yogyakarta: Graha Ilmu.

Mc Leod, R. (2003). Sistem Informasi Manajement Edisi 8. Jakarta: Index.

Fitriyani, N. (2011). RANCANG BANGUN SISTEM INFORMASI AKADEMIK (STUDI KASUS: YAYASAN PESANTREN TARBIYAH NURUL. Fakultas Sains Dan Teknologi,
Universitas Islam Negeri Syarif Hidayatullah Jakarta .

Jamaliyah. (2011). Sistem Informasi Akademik Berbasis Client Server (Studi Kasus: Madrasah Tsanawiyah AnNizhamiyyah Cileungsi). Fakultas Sains Dan Teknologi, Universitas Islam Negeri Syarif Hidayatullah Jakarta. Hadi, S. (2010 йил 8-Mei). Pengertian dan tipe pesantren. Retrieved 2015 йил 6-Juni from Sopwan Hadi's File:

https://www.sopwanhadi.wordpress.co $\mathrm{m} / 2010 / 05 / 08 /$ pengertian-dan-tipepesantren/

Sibero, A. (2011). Kitab Suci Web Programing. Jakarta: Mediakom.

Kustiyahningsih, Y. (2011). Pemrograman Basis Data Berbasis Web Menggunakan PHP \& MySQL. Jakarta: Graha Ilmu.

Prihatna, H. (2005). Kiat Praktis Menjadi Webmaster Profesional. Jakarta: Alex Media Komputindo.

Komputer, W. (2010). Membuat Aplikasi Client Server dengan Visual Basic 2008. Yogyakarta: Andi Ofset.

Munawar. (2005). Permodelan Visual dengan $U M L$. Yogyakarta: Pustaka Pelajar.

Narcissa, O. (2012 йил 13-September). Unified Modeling Language (UML). Retrieved 2015 йил 28-Juni from Punya Olia: http://punyaolia.blogspot.com/2012/09/unifiedmodeling-language-uml.html

Arian, Т. (2013 йил 11-3). Pengertian website. Retrieved 2015 йил 7-2 from Welcome to my world:

http://tegararian.blogspot.com/2013/03/ pengertian-website.html

Masud. (2014 йил 2-7). Pondok Pesantren Sebagai lembaga Pendidikan Islam. Retrieved 2015 йил 4-7 from Berita Islami Masa Kini:

http://beritaislamimasakini.com/pondo k-pesantren-sebagai-lembagapendidikan-islam.htm

Kendall, K. E., \& Kendal, J. E. (2003). Analisis dan Perancangan Sistem. Jakarta: Indeks.

Rajab, M. N. (2014). Perancangan Sistem Informasi Akademik Berbasis Web pada SMK Negeri 1 Limbung Kabupaten Gowa. Skripsi . 
<smiles>CCCCCCC</smiles> 